\title{
Population correlates of circulating mercury levels in Korean adults: the Korea National Health and Nutrition Examination Survey IV
}

\author{
Seongbeom Cho' ${ }^{1}$ David R Jacobs $\mathrm{Jr}^{2}$ and Kyong Park ${ }^{3 *}$
}

\begin{abstract}
Background: Prior studies focused on bioaccumulation of mercury $(\mathrm{Hg})$ and on large, long-lived fish species as the major environmental source of $\mathrm{Hg}$, but little is known about consumption of small-sized fish or about non-dietary determinants of circulating $\mathrm{Hg}$ levels. The purpose of this study was to evaluate whole blood mercury concentration (WBHg) and its major dietary and non-dietary correlates in Korean adults.

Methods: We analyzed cross-sectional data from 3,972 (male $=1,994$; female $=1,978$ ) participants who completed the Korean National Health and Nutrition Examination Survey IV, 2008 to 2009. Relevant factors included diet, geographic location of residence, demographics, and lifestyle. WBHg concentration was measured using cold-vapor atomic absorption spectrometry. Multivariable linear models assessed independent correlates of dietary and non-dietary factors for WBHg levels.

Results: Median levels of WBHg were $5.1 \mu \mathrm{g} / \mathrm{L}$ in men and $3.7 \mu \mathrm{g} / \mathrm{L}$ in women. Higher levels of fish/shellfish intake were associated with higher levels of WBHg. Higher consumption of small-sized fish was linked to higher levels of WBHg. Non-dietary predictors of higher WBHg were being male, greater alcohol consumption, higher income and education, overweight/obesity, increasing age, and living in the southeast region.

Conclusions: Both dietary and non-dietary factors were associated with WBHg levels in the Korean population. There is significant geographic variation in WBHg levels; residents living in the mid-south have higher WBHg levels. We speculate that uncontrolled geographic characteristics, such as local soil/water content and specific dietary habits are involved.
\end{abstract}

Keywords: Blood mercury, Correlates, Fish intake, Korean adults

\section{Background}

Fish consumption is relatively high and has been increasing steadily in the Asian population [1-3]. Fish intake is a major source of mercury $(\mathrm{Hg})$ exposure in humans. $\mathrm{Hg}$ is a heavy metal that is released into the air from coal-fired power plants and other industrial processes, and bioaccumulates in the marine food chain, binding to tissue proteins depending on body size, lifespan, or levels of environmental contamination.

The potential independent correlates of $\mathrm{Hg}$ have not been well-characterized in Korea. There may be differences in

\footnotetext{
* Correspondence: kypark@ynu.ac.kr

${ }^{3}$ Department of Food and Nutrition, Yeungnam University, Gyeongsan, Gyeongbuk, Republic of Korea

Full list of author information is available at the end of the article
}

human $\mathrm{Hg}$ concentrations depending on socio-economic level [4], residential area [4-6], traditional culture or ethnicity [4,7-9], lifestyle characteristics [10], and the types of fish and seafood typically consumed [6,9]. Prior Korean $\mathrm{Hg}$ studies have generally focused on the acute toxic effects of $\mathrm{Hg}$ [11-13] and have been conducted in geographically limited areas [14-16]. Others have simply presented the average levels in subjects without considering the types of seafood or geographic variations [17-19].

Understanding the independent dietary and non-dietary determinants of $\mathrm{Hg}$ status is important for elucidating the biologic mechanisms related to chronic exposure to $\mathrm{Hg}$ and for identifying potential interventions that might improve the health benefits of fish consumption. The present study examined both dietary and non-dietary correlates of 
Hg status in a cross-sectional sample of 3,397 Korean men and women aged 20-87 years who participated in the Korea National Health and Nutrition Examination Survey (KNHANES IV). Generally, Korean adults frequently consume fish in greater quantities than do Western populations [1-3]. Thus, we identified the types of fish most frequently consumed and associated with higher levels of whole blood mercury concentration (WBHg), and investigated the independent demographic, lifestyle, and geographic determinants of WBHg levels.

Methyl mercury, mostly from fish intake, may accumulate over time in human muscle tissue, so is expected to be positively correlated with age. Region-specific dietary habits may also be related to $\mathrm{Hg}$ levels, such as serving whale/shark meat in dishes for a traditional ceremony or locally caught types of fish. In addition, there is now widespread concern over red meat consumption among middle aged Korean population, who tend to reject red meat in favor of other alternatives such as fish, particularly sashimi for alcohol dishes. Considering these characteristics, we hypothesized that $\mathrm{Hg}$ levels are closely associated with higher intakes of small marine fish as well as large predator species in the population with high and varied fish consumption, and some geographic variation can be observed, controlling diet.

\section{Methods}

\section{Population and design}

We analyzed data from the KNHANES IV (2008-2009), a nationwide cross-sectional survey, using a complex, stratified, multistage, probability-cluster sampling of the non-institutionalized civilian population in South Korea. Details of this survey can be found elsewhere [20,21]. Briefly, the survey collected extensive information on health and nutritional status through health interviews, health examinations, and dietary interviews administered by trained personnel. For the two years covered by the survey, there were 20,277 respondents; 9,744 in 2008 and 10,533 in 2009. KNHANES randomly selected $20 \%$ of participants at each examination to evaluate their whole blood levels of heavy metals. In this analysis, we included all participants with WBHg whose ages ranged from 20 to 87 years $(n=3,996)$. Among them, we excluded 1 individual with WBHg concentration $>150 \mu \mathrm{g} / \mathrm{L}$ that could reflect exogenous contamination and 23 pregnant women. All participants provided written consent and the study was approved by the Korea Centers for Disease Control and Prevention Institutional Review Board.

\section{Assessment of WBHg levels}

Before blood was drawn, participants were asked to fast overnight. Venous blood samples were drawn into standard commercial evacuated tubes containing sodium heparin (vacutainer). Whole blood $\mathrm{Hg}$ measurements were performed by a gold-amalgam collection method with DMA-80 (Milestone, Bergamo, Italy); measurements took place at the Neodin Medical Institute in South Korea. Laboratory personnel were blinded to all participant characteristics and intra-assay variability was excellent with $\mathrm{CV}=$ $1.59-4.86 \%$.

\section{Assessment of dietary, lifestyle and geographic information}

Dietary information was estimated using a food frequency questionnaire (FFQ) and a 24-hour dietary recall test. The KNHANES used a 63-item FFQ, non-quantitative in the sense that portion size information was not queried. We therefore quantified levels of fish and shellfish consumption in two separate ways: (1) by frequency according to the FFQ and (2) by recording daily intake levels from a 24-hour recall. The FFQ listed nine items regarding the frequency of fish consumption and shellfish most frequently consumed by South Koreans: mackerel, tuna, yellow fish, pollock, anchovy, seafood paste, squid, clam, and pickled seafood. Items on the FFQ were rated on a Likerttype scale ranging from "rarely" to " 3 times a day", and the frequency per food item was converted into times per week using median values. In order to obtain daily intake levels of fish and shellfish, we identified the marine species consumed by at least $1 \%$ of all participants $(n=3972)$ in the present sample and then calculated the individual intake levels for each item using 24-hour recall data. Consumption of tuna was estimated separately by the product preparation method (for example, canned and fresh/sashimi) because levels of $\mathrm{Hg}$ differ substantially according to the type of species used [21,22].

Information on demographic and lifestyle factors including age, sex, income, education, smoking, alcohol consumption, and physical activity was obtained through a health interview questionnaire. Education level was categorized as middle school or less, high school, and college or more. Smoking status was classified as never, former, or current smoker. Alcohol consumption was quantified as servings per week. Participants were asked how much time they had spent in vigorous and moderate activities and walking during the past week; activities were then weighted by frequency and duration in order to obtain the metabolic equivalents (METs)-h/week [23]. A trained technician took anthropometric measurements, including waist circumference, height, and weight. Body mass index (BMI) was calculated as weight $(\mathrm{kg})$ divided by height $\left(\mathrm{m}^{2}\right)$ squared. "Overweight/obesity" was defined based on 2000 statement from the World Health Organization for Asian population: the BMI cutoff value for overweight was $23 \mathrm{~kg} / \mathrm{m}^{2}$ and for obesity was $25 \mathrm{~kg} / \mathrm{m}^{2}$ [24]. Waist circumference $(\mathrm{cm})$ was measured as the abdominal girth midway between the iliac crest and the bottom of the rib cage, with the arms relaxed at the sides. Participants were 
asked to report the frequency of eating out, ranging from "rarely" to " 2 times a day" in 5 categories, and ratings were converted into a "times per week" measure. Residential areas were evaluated separately and then grouped into 5 geographic regions based on similarities of both WBHg levels and geographic location: north (Seoul, Incheon, Gyeonggi-do, Gangwon-do), midwest (Daejeon, Chungcheongbuk-do, Chungcheongnam-do), mideast (Daegu, Gyeongsangbuk-do), southwest (Gwangju, Jeollabuk-do, Jeollanam-do), and southeast and island (Busan, Ulsan, Gyeongsangnam-do, Jeju island).

\section{Statistical analysis}

A multivariable linear regression was used to examine associations of fish intake, demographic factors, and lifestyle factors, with log-transformed WBHg level as the dependent variable. For categorical variables, the Chi-square statistic was computed to compare participant characteristics with quartiles of WBHg. Population means for fish and shellfish daily consumptions were estimated and compared with quartiles of WBHg using generalized linear regression analyses. Region-specific WBHg levels were estimated and adjusted for age, sex, BMI, physical activity, smoking status, alcohol intake, household income, fish intake level (g/day), and frequency of eating out. Effect modification of the associations was tested by cross-product terms, and no significant interaction was found. Because the study analyzed data collected using a stratified, multistage probability sampling design (the KNHANES), all analyses were performed using survey procedures in $\mathrm{SAS}^{\circ}$ (version 9.2). For all tests, the critical value for $p$ was set at $\alpha=0.05$, two-tailed.

\section{Results}

Table 1 gives demographic characteristics of the study participants sorted by sex (1,994 men, 1,978 women). The median concentration of WBHg was $5.1 \mu \mathrm{g} / \mathrm{L}$ in men and $3.7 \mu \mathrm{g} / \mathrm{L}$ in women. Distributions of age, income level, and residential area did not differ by sex. The prevalence of overweight/obesity and smoking was significantly greater in men than in women. In addition, men were more likely to frequently consume alcohol and eat out and to have higher levels of physical activity (MET-h/week) and education compared to women.

Table 2 summarizes $\mathrm{Hg}$ levels by quartile and according to demographic characteristics. The highest levels of WBHg were recorded in individuals in the 40-59-year-old age group. Higher levels of WBHg were associated with overweight/obesity, current smoking, frequent alcohol drinking and eating out, higher levels of income and education, and residence in the mideast or southeast/island areas of South Korea.

Table 3 gives the most frequently consumed species of fish listed according to the levels of WBHg in the present study sample. Overall, higher intakes of white fish were associated with higher levels of WBHg. In particular, consumption of both yellow corvina $(\mathrm{p}<0.01)$ and halibut $(\mathrm{p}<0.001)$ were significantly associated with higher levels of WBHg and showed dose-response relationships. Intake of most oily fish types showed positive associations with levels of WBHg. Among oily fish, anchovy and mackerel were most frequently consumed and also showed significant positive associations with levels of WBHg ( $\mathrm{p}=0.01$ and $\mathrm{p}<0.01$, respectively). Consumption of fresh tuna was significantly associated with higher levels of WBHg $(\mathrm{p}<0.001)$ whereas consumption of canned tuna was not $(\mathrm{p}=0.4)$. In Table 3 , the values may have high within person variance due to single 24 hour recall, rather than multiple measurements.

Table 4 provides comparisons of levels of fish and shellfish consumption for weekly (FFQ) and daily (24-hour recall) intake and according to WBHg levels. Higher levels of fish and shellfish intake were associated with higher levels of WBHg, according to both consumption measures. These associations were particularly evident in the consumption of white fish, oily fish, and shellfish $(\mathrm{p}<0.001)$.

To understand whether lifestyle and environmental factors were associated with WBHg after accounting for fish and shellfish consumption, we conducted multivariableadjusted linear regression analyses for each of the identified dietary and non-dietary factors (Table 5). Both age and gender were independent correlates of WBHg levels, even after adjusting for diet as well as other lifestyle and environmental factors. WBHg levels ranged from 11.1$12.9 \%$ higher in 40-59-year-olds than in 20-29-year-olds $(\mathrm{p}<0.001)$; WBHg levels were also $9.8 \%$ higher in men than in women $(\mathrm{p}<0.001)$. Several lifestyle factors were also independently associated with WBHg levels. Higher BMI was associated with higher WBHg levels, with $1.0 \%$ higher levels for each additional $1 \mathrm{~kg} / \mathrm{m}^{2}(\mathrm{p}<0.001)$. Higher alcohol consumption was associated with higher WBHg levels with a dose-response relationship showing that, when compared to non-drinkers, levels were 9.49.7\% higher in drinkers who had alcohol intake at least twice per week $(\mathrm{p}<0.001)$. Income and education levels were also positively associated with WBHg levels, such that high-income, highly-educated participants were more likely to have higher levels of WBHg. Compared with participants in the lowest quartile of household income, those in the highest quartile had 8.1\% higher WBHg levels ( $\mathrm{p}<$ 0.001). In addition, participants with college/university education or higher had 3.7\% higher WBHg levels compared to those with middle school education or less ( $p<0.01)$. Even after adjustment for each of these lifestyle factors and types of fish and shellfish consumption, we identified significant geographic variation in WBHg levels. Compared to participants living in the midwest regions of South Korea (the lowest WBHg region), those living in the southeast/island, mideast, southwest, and north, had 
Table 1 Demographic characteristics of participants from the KNHANES (2008-2009)

\begin{tabular}{|c|c|c|c|c|c|c|}
\hline & \multirow[t]{2}{*}{$\mathbf{N}$} & \multicolumn{4}{|c|}{ Sex } & \multirow[t]{2}{*}{ p-value } \\
\hline & & \multicolumn{2}{|c|}{ Men $(n=1994)$} & \multicolumn{2}{|c|}{ Women $(n=1978)$} & \\
\hline Range of mercury $(\mu \mathrm{g} / \mathrm{L})$ & 3972 & \multicolumn{2}{|c|}{$0.90-56.97$} & \multicolumn{2}{|c|}{$0.88-33.93$} & - \\
\hline Mean mercury $(\mu \mathrm{g} / \mathrm{L})$ & 3972 & 6.32 & \pm 0.12 & 4.25 & \pm 0.07 & $<0.001$ \\
\hline Age (years, \%) & & & & & & 0.9 \\
\hline $20-29$ & 775 & 396 & (20) & 379 & (19) & \\
\hline $30-39$ & 795 & 404 & (20) & 391 & (20) & \\
\hline $40-49$ & 800 & 400 & (20) & 400 & (20) & \\
\hline $50-59$ & 790 & 391 & (20) & 399 & (20) & \\
\hline$\geq 60$ & 812 & 403 & (20) & 409 & (21) & \\
\hline Overweight/obesity (BMI $\geq 23, \%)$ & 1242 & 691 & (35) & 551 & (28) & $<0.001$ \\
\hline Smoking status (\%) & & & & & & $<0.001$ \\
\hline Never & 2126 & 395 & (20) & 1731 & (87) & \\
\hline Former & 807 & 695 & (35) & 112 & (6) & \\
\hline Current & 1033 & 899 & (45) & 134 & (7) & \\
\hline Alcohol intake (n/week) & 3964 & 1.33 & \pm 0.03 & 0.53 & \pm 0.02 & $<0.001$ \\
\hline MET-h/week & & & & & & $<0.001$ \\
\hline$<20$ & 1693 & 747 & (38) & 946 & (48) & \\
\hline 20-39 & 763 & 389 & (20) & 374 & (19) & \\
\hline$\geq 40$ & 1493 & 846 & (42) & 647 & (33) & \\
\hline Eating-out (n/week) & 3450 & 5.26 & \pm 0.13 & 2.90 & \pm 0.10 & $<0.001$ \\
\hline Income level (\%) & & & & & & 0.1 \\
\hline Low & 1004 & 498 & (26) & 506 & (26) & \\
\hline Mid low & 968 & 481 & (25) & 487 & (25) & \\
\hline Mid high & 965 & 461 & (24) & 504 & (26) & \\
\hline High & 964 & 512 & (26) & 452 & (23) & \\
\hline Education (\%) & & & & & & $<0.001$ \\
\hline Middle school or less & 1340 & 556 & (28) & 784 & (40) & \\
\hline High school & 1490 & 782 & (40) & 708 & (36) & \\
\hline College or more & 1125 & 642 & (32) & 483 & (24) & \\
\hline Residence area (\%) & & & & & & 0.9 \\
\hline Midwest & 475 & 234 & (12) & 241 & (12) & \\
\hline North & 1873 & 944 & (47) & 929 & (47) & \\
\hline Southwest & 504 & 248 & (13) & 256 & (13) & \\
\hline Mideast & 422 & 207 & (10) & 215 & (11) & \\
\hline Southeast and an island & 698 & 361 & (18) & 337 & (17) & \\
\hline
\end{tabular}

Values are $\mathrm{n}(\%)$ or mean $\pm \mathrm{SE}$, except the range of mercury.

significantly higher WBHg levels (southeast/island: $17.5 \%$ higher, $\mathrm{p}<0.001$; mideast: $16.5 \%$ higher, $\mathrm{p}<0.001$; southwest: $8.7 \%$ higher, $\mathrm{p}<0.001$; north: $5.5 \%$ higher, $\mathrm{p}<0.001)$.

To further examine regional differences, we calculated adjusted means of WBHg levels for each province in South Korea (Figure 1). Overall, participants in the southeast/island region appeared to have higher levels of WBHg than those in northwestern regions. The highest levels (adjusted means) of WBHg were found in Gyeongsangbuk-do $(7.6 \mu \mathrm{g} / \mathrm{L})$, Jeju $(7.3 \mu \mathrm{g} / \mathrm{L})$, Ulsan $(7.1 \mu \mathrm{g} / \mathrm{L})$, and Daegu $(7.0 \mu \mathrm{g} / \mathrm{L})$. Regions with the lowest levels (adjusted means) of WBHg were Daejeon $4.4 \mu \mathrm{g} / \mathrm{L}$, Chungcheongbuk-do $4.4 \mu \mathrm{g} / \mathrm{L}$, and Chungcheongnam-do $4.7 \mu \mathrm{g} / \mathrm{L}$. None of these regional findings differed by age or sex. 
Table 2 Demographic characteristics of participants from the KNHANES (2008-2009), according to quartile of blood mercury levels $(n=3972)$

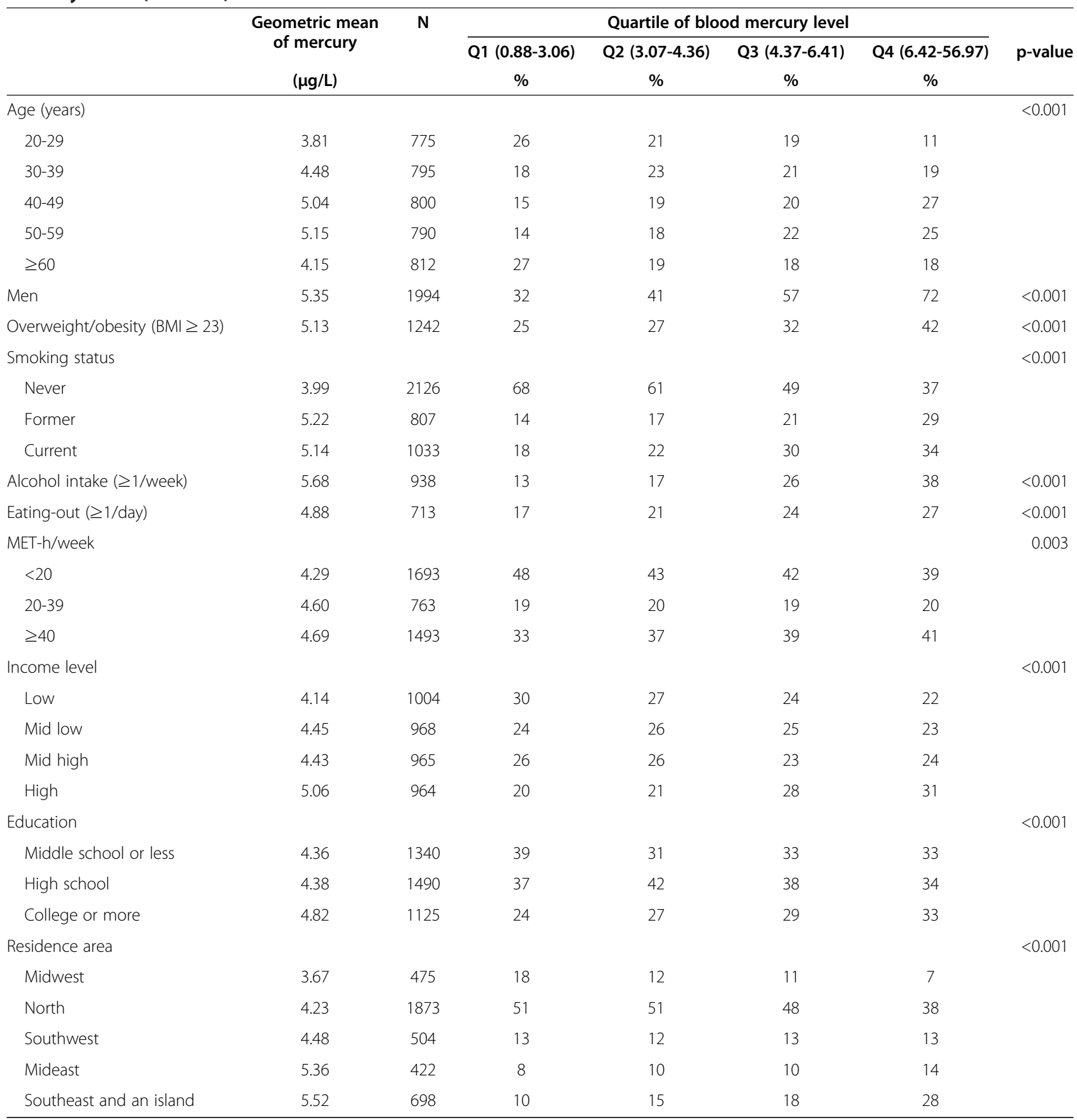

\section{Discussion}

In this cross-sectional analysis of the general Korean population, several independent correlates of WBHg levels were identified. As expected, participants with higher intakes of fish and shellfish had significantly higher levels of WBHg and the pattern of association was a dose-response relationship. In addition, independent effects of other demographic and lifestyle factors, such as gender, age, obesity, alcohol consumption, and income and education levels were identified, accounting for the levels of fish and shellfish consumption.

Park and Lee have previously examined the association between WBHg and seafood intake levels, using 9 items from the non-quantitative FFQ of KNHANES 
Table 3 Daily fish and shellfish consumption levels according to blood mercury levels in a sample $(n=3972)$ from the KNHANES (2008-2009); data from 24-hour recall

\begin{tabular}{|c|c|c|c|c|c|c|c|c|}
\hline & \multirow{2}{*}{$\begin{array}{c}\text { Population } \\
\text { mean }^{\mathrm{a}}\end{array}$} & \multirow{2}{*}{$\begin{array}{c}\text { Consumer } \\
\text { mean }^{b}\end{array}$} & \multirow{2}{*}{$\begin{array}{l}\text { Number of } \\
\text { consumers }\end{array}$} & \multicolumn{4}{|c|}{ Quartile of blood mercury level ${ }^{a}$} & \multirow{2}{*}{$\begin{array}{l}P \text { for } \\
\text { trend }\end{array}$} \\
\hline & & & & Q1 & Q2 & Q3 & Q4 & \\
\hline \multicolumn{9}{|l|}{ White fish } \\
\hline Pollock ${ }^{c}$ & 5.8 & 56.8 & 354 & 4.4 & 4.8 & 7.7 & 6.2 & 0.1 \\
\hline Yellow corvina & 3.3 & 57.0 & 203 & 2.4 & 3.0 & 3.1 & 4.8 & 0.006 \\
\hline Cutlassfish & 1.6 & 37.8 & 143 & 0.9 & 1.9 & 1.6 & 1.8 & 0.2 \\
\hline Halibut & 1.2 & 83.0 & 49 & 0.6 & 0.8 & 0.8 & 2.5 & $<0.001$ \\
\hline Cod & 0.4 & 40.7 & 34 & 0.2 & 0.3 & 0.5 & 0.6 & 0.1 \\
\hline Flounder & 0.5 & 57.2 & 28 & 0.4 & 0.7 & 0.5 & 0.3 & 0.6 \\
\hline Sea bream & 0.7 & 91.5 & 28 & 0.7 & 0.7 & 0.5 & 1.1 & 0.6 \\
\hline Monk fish & 0.5 & 102.4 & 18 & 0.2 & 0.5 & 0.9 & 0.6 & 0.3 \\
\hline Arabesque greenling & 0.5 & 112.2 & 15 & 0.9 & 0.2 & 0.7 & 0.1 & 0.3 \\
\hline \multicolumn{9}{|l|}{ Oily/fatty fish } \\
\hline Anchovy & 7.3 & 15.1 & 1691 & 6.8 & 6.7 & 7.5 & 8.3 & 0.01 \\
\hline Mackerel $^{c}$ & 5.5 & 64.1 & 298 & 4.0 & 5.0 & 5.7 & 7.3 & 0.009 \\
\hline Pacific saury & 1.6 & 67.9 & 83 & 1.1 & 2.8 & 1.6 & 0.9 & 0.4 \\
\hline Eel & 1.2 & 64.4 & 66 & 1.2 & 1.0 & 0.8 & 1.9 & 0.3 \\
\hline Tuna (fresh) & 0.9 & 58.6 & 53 & 0.5 & 0.3 & 0.8 & 2.0 & $<0.001$ \\
\hline Salmon & 0.2 & 28.8 & 30 & 0.1 & 0.2 & 0.3 & 0.4 & 0.08 \\
\hline Spanish mackerel & 0.5 & 80.9 & 22 & 0.1 & 0.5 & 1.2 & 0.3 & 0.7 \\
\hline \multicolumn{9}{|l|}{ Other fish } \\
\hline Fish paste & 5.3 & 36.5 & 506 & 5.1 & 5.7 & 4.9 & 5.6 & 0.8 \\
\hline Tuna (canned) & 1.6 & 35.9 & 154 & 1.7 & 1.1 & 1.7 & 1.9 & 0.4 \\
\hline Skate & 0.9 & 75.6 & 42 & 0.4 & 1.4 & 1.0 & 0.8 & 0.9 \\
\hline Rockfish & 0.5 & 44.7 & 41 & 0.3 & 0.6 & 0.3 & 0.9 & 0.1 \\
\hline Filefish & 0.5 & 48.9 & 39 & 0.1 & 0.3 & 0.7 & 1.1 & 0.003 \\
\hline Loach & 0.8 & 89.6 & 33 & 0.6 & 0.8 & 1.0 & 1.0 & 0.5 \\
\hline
\end{tabular}

${ }^{a}$ Mean consumption ( $\mathrm{g} /$ day; includes that of non-consumers) of fish and seafood. Total intake level of each food item divided by total $\mathrm{N}$.

${ }^{b}$ Mean consumption ( $\mathrm{g} /$ day; including only consumers) of fish and seafood. Total intake level of each food item divided by consumer $\mathrm{N}$.

${ }^{c}$ Mackerel and Pollock were independent correlates of whole blood mercury in a multivariable-adjusted analysis, including adjustments for all fish items asked in

FFQ. This multivariable-adjusted analysis was conducted using FFQ data.

[25]. We supplemented the non-quantitative and less detailed information from the FFQ with quantitative and detailed information from the single $24 \mathrm{~h}$ dietary recall, thus more fully using available KNHANES dietary information, to estimate the usual amounts of fish and seafood consumption and to add detail to the types of fish and seafood that are commonly consumed in this population. In addition, Lee et al. suggested that residents in coastal areas have relatively high levels of WBHg due to higher consumption of seafood [6]. However, our study found a significant geographic variation in WBHg levels among coastal participants even after adjusting for multiple factors.

Our study highlighted some important findings concerning $\mathrm{Hg}$ levels in large and small marine fish species and their relationship to $\mathrm{Hg}$ levels in humans. Previously, public health concern has been focused on exposure to $\mathrm{Hg}$ due to consumption of large predator species such as shark, swordfish, king mackerel, or tilefish $[26,27]$. However, in the present study, the most frequently consumed small marine species such as mackerel were associated with substantially higher WBHg levels in the Korean population. Thus, it is important to improve understanding of chronic exposure to $\mathrm{Hg}$ from frequently consumed small marine species. This is especially critical for populations such as Koreans, where there is high consumption of a variety of fish (of both small and large species) and shellfish. Given Korean meal patterns, correlation is expected between large and small fish intake. However, we observed higher 
Table 4 Levels of fish and shellfish consumption in a participant sample $(n=3972)$ from the KNHANES (2008-2009) according to blood mercury levels

\begin{tabular}{|c|c|c|c|c|c|c|c|c|}
\hline & \multirow{2}{*}{$\begin{array}{l}\text { Population } \\
\text { mean }^{\mathrm{a}}\end{array}$} & \multirow{2}{*}{$\begin{array}{c}\text { Consumer } \\
\text { mean }^{b}\end{array}$} & \multirow{2}{*}{$\begin{array}{l}\text { Number of } \\
\text { consumers }\end{array}$} & \multicolumn{4}{|c|}{ Quartile of blood mercury level ${ }^{\mathrm{a}}$} & \multirow{2}{*}{$\begin{array}{l}\mathrm{P} \text { for } \\
\text { trend }\end{array}$} \\
\hline & & & & Q1 & Q2 & Q3 & Q4 & \\
\hline \multicolumn{9}{|l|}{ Intake levels from $24-\mathrm{h}$ recall (g/day) } \\
\hline Total fish ${ }^{c}$ & 41.4 & 58.7 & 2458 & 32.9 & 39.4 & 43.8 & 50.0 & $<0.001$ \\
\hline White fish & 14.4 & 65.2 & 770 & 10.7 & 12.9 & 16.3 & 17.9 & $<0.001$ \\
\hline Oily/fatty fish & 17.3 & 31.5 & 1909 & 13.8 & 16.6 & 18.0 & 21.0 & $<0.001$ \\
\hline Other fish & 9.7 & 46.1 & 735 & 8.3 & 9.9 & 9.5 & 11.2 & 0.08 \\
\hline Shellfish and other seafood ${ }^{d}$ & 17.9 & 42.8 & 1452 & 13.7 & 16.9 & 17.9 & 23.2 & $<0.001$ \\
\hline \multicolumn{9}{|l|}{ Intake levels from FFQ (n/week) } \\
\hline Total fish ${ }^{e}$ & 5.1 & 5.1 & 3382 & 4.4 & 5.2 & 5.2 & 5.6 & $<0.001$ \\
\hline White fish (yellow corvina, pollock) & 1.1 & 1.2 & 3088 & 0.8 & 1.0 & 1.1 & 1.3 & $<0.001$ \\
\hline Oily/fatty fish (mackerel, anchovy) & 2.9 & 3.0 & 3306 & 2.5 & 3.0 & 2.9 & 3.2 & $<0.001$ \\
\hline Other fish (tuna, fish paste) & 1.1 & 1.9 & 2759 & 1.05 & 1.14 & 1.14 & 1.09 & 0.8 \\
\hline Shellfish and other seafood (squid, clam, pickled seafood) & 1.7 & 1.9 & 3127 & 1.3 & 1.6 & 1.9 & 2.1 & $<0.001$ \\
\hline
\end{tabular}

${ }^{a}$ Mean consumption (includes that of non-consumers) of fish and seafood. Total intake level of each food item divided by total $\mathrm{N}$.

${ }^{\mathrm{b}}$ Mean consumption (including only consumers) of fish and seafood. Total intake level of each food item divided by consumer $\mathrm{N}$.

'Sum of the intake of top 22 fish types (anchovy, fish paste, pollock, mackerel, yellow corvina, tuna (canned), cutlassfish, pacific saury, eel, tuna (fresh only), halibut, skate, rockfish, filefish, cod, loach, salmon, flounder, sea bream, Spanish mackerel, monk fish, and arabesque greenling).

${ }^{d}$ Sum of the intake of shellfish and other seafood (clam, crawfish, crab, whelk, oyster, shrimp, conch, abalone, mussel, squid, octopus, jellyfish, sea cucumber, sea squirt, fish intestine, salted seafood).

'Sum of the frequency of consumption of mackerel, tuna (fresh and canned), yellow corvina, pollock, anchovy, and fish paste.

WBHg in a multivariable-adjusted analysis, including simultaneous adjustment for all fish items asked in FFQ. Tuna, one of the most frequently consumed fish in Korea and worldwide, is known to be a major source of $\mathrm{Hg}[9,22]$. Interestingly, our study showed that higher consumption of canned tuna was not associated with elevated levels of WBHg, whereas consumption of fresh tuna, such as sashimi or sushi, was associated with significantly higher levels of WBHg. The reason is unknown, but this may be related to the types of tuna since the majority of canned tuna available in the Korean market is "light-style" tuna consisting mainly of skipjack (Katsuwonus pelamis), whereas the bluefin tuna is commonly used for sashimi or sushi [28,29]. Our study results are consistent with previous research indicating that bluefin tuna has higher concentrations of $\mathrm{Hg}$ than does canned light tuna [22].

Several demographic and lifestyle determinants of WBHg were identified. Men had higher WBHg concentrations than women, consistent with previous findings [30]. In addition, alcohol consumption, income, and education levels were significant correlates of WBHg concentrations. The association of WBHg with alcohol is grouped here with demographic variables because many Koreans have dinner/ drink meetings after work. In the face of concern about meat eating, this behavior may link alcohol and fish/sashimi consumption.
In our study, WBHg levels were positively associated with BMI after controlling for other variables. While recent study findings argue that the benefits of fish consumption may outweigh the negative effects of chronic exposure to $\mathrm{Hg}[26,31]$, particularly for cardiovascular health outcomes, the association between $\mathrm{Hg}$ exposure and overweight/obesity is not well established. Indeed, our findings contradict those of previous studies. In a study with a Brazilian sample [32], Hg exposure from fish consumption was not associated with BMI. Further, a study of the Korean elderly population residing in coastal areas showed that the waist-hip ratio was significantly correlated with blood $\mathrm{Hg}$ concentration, but BMI was not [19]. Thus, the mechanism of association between $\mathrm{Hg}$ exposure and overweight/obesity is relatively understudied and further research is warranted.

The present study found significant geographic variation in WBHg levels. South Korea is surrounded by ocean water with a long coast line on three sides. Thus, seafood is easily accessible from almost any region. Indeed, residents in a few regions, mostly located in the center of the Korean peninsula, had relatively low levels of $\mathrm{WBHg}$ when compared to regions located closer to the coast line. However, even after adjustment for multiple factors including fish and shellfish intake levels, significant geographic variation remained in WBHg levels. This may be due to other uncontrolled geographic characteristics, such as the type of marine 
Table 5 Dietary and non-dietary correlates of whole blood mercury ${ }^{a}$ in a participant sample $(n=3972)$ from the KNHANES (2008-2009) ${ }^{\mathrm{b}}$

\begin{tabular}{lcc}
\hline & $\begin{array}{c}\text { \% difference in } \\
\text { blood mercury }\end{array}$ & p-value \\
\hline Age (years) & Reference & \\
$20-29$ & 6.0 & $<0.001$ \\
$30-39$ & 11.1 & $<0.001$ \\
$40-49$ & 12.9 & $<0.001$ \\
$50-59$ & 5.6 & $<0.001$ \\
$\geq 60$ & 9.8 & $<0.001$ \\
Men & 1.0 & $<0.001$ \\
BMI $\left(\mathrm{kg} / \mathrm{m}^{2}\right)$ & & \\
White fish intake level $(\mathrm{g} /$ day $)$ & Reference & \\
Low tertile $(0)$ & 2.7 & 0.02 \\
Medium tertile $(0<-\leq 40)$ & 3.9 & $<0.001$ \\
High tertile $(>40)$ & &
\end{tabular}

Oily/fatty fish intake level (g/day)

Low tertile (0)

Medium tertile $(0<-\leq 40)$

High tertile (>40)

Reference

$\begin{array}{ll}1.6 & 0.05 \\ 2.6 & 0.03\end{array}$

Total shellfish intake level ( $g /$ day)

Low tertile (0)

Medium tertile $(0<-\leq 20)$

High tertile (>20)

MET-h/week

$<20$

20-39

$\geq 40$

Smoking status

Never

Former

Current

Alcohol intake

Never

$\leq 1 / \mathrm{mo}$

$\leq 1 /$ week

2-3/week

4+/week

Income

Low

Mid low

Mid high

High
Reference

$-1.4$

3.2

Reference

$$
2.6
$$

0.8

Reference

$$
0.9
$$

1.7

Reference

$\begin{array}{cc}1.7 & 0.1 \\ 4.7 & <0.001 \\ 9.4 & <0.001 \\ 9.7 & <0.001\end{array}$

Reference

$\begin{array}{lc}3.0 & 0.004 \\ 4.2 & <0.001 \\ 8.1 & <0.001\end{array}$

Table 5 Dietary and non-dietary correlates of whole blood mercury ${ }^{a}$ in a participant sample $(n=3972)$ from

\begin{tabular}{|c|c|c|}
\hline \multicolumn{3}{|l|}{ Education } \\
\hline Middle school graduation or less & Reference & \\
\hline High school graduation & 0.4 & 0.7 \\
\hline College or more & 3.7 & 0.003 \\
\hline \multicolumn{3}{|l|}{ Residence area } \\
\hline Midwest & Reference & \\
\hline North & 5.5 & $<0.001$ \\
\hline Southwest & 8.7 & $<0.001$ \\
\hline Mideast & 16.5 & $<0.001$ \\
\hline Southeast and an island & 17.5 & $<0.001$ \\
\hline
\end{tabular}
the KNHANES (2008-2009) ${ }^{\text {b }}$ (Continued)

species consumed, water or soil content, local ceremonial traditions or specific dietary habits (e.g., serving dishes containing whale and/or shark meat).

Our study analyzed data from the KNHANES containing data representative of random samples of the South Korean population and therefore may be generalizable to the larger population of Korean adults. In addition, we provide multivariable-adjusted estimates of $\mathrm{WBHg}$, thus minimizing residual confounding while evaluating multiple potential determinants in the Korean population. Our analysis showed how each of the recorded demographic, lifestyle, geographic, and dietary factors may correlate independently with WBHg levels.

A limitation of the present study is that $\mathrm{Hg}$ levels were evaluated in whole blood and thus may indicate a relatively short-term exposure to $\mathrm{Hg}$ compared to other biomarkers such as hair or toenails. It is also possible that, although the present study evaluated multiple variables that were estimated using standardized instruments, residual confounding could still exist due to the presence of unmeasured or imperfectly measured factors. In addition, fish and seafood intake levels were evaluated using one-day 24-hour recall and the nonquantitative FFQ questionnaire, leaving open the possibility of misclassification.

\section{Conclusions}

In summary, in addition to fish consumption, we identified several demographic and lifestyle determinants of WBHg in the Korean population. Furthermore, Koreans tend to consume large amounts of small marine species and consumption of these species was positively associated with levels of WBHg, showing dose-response type 

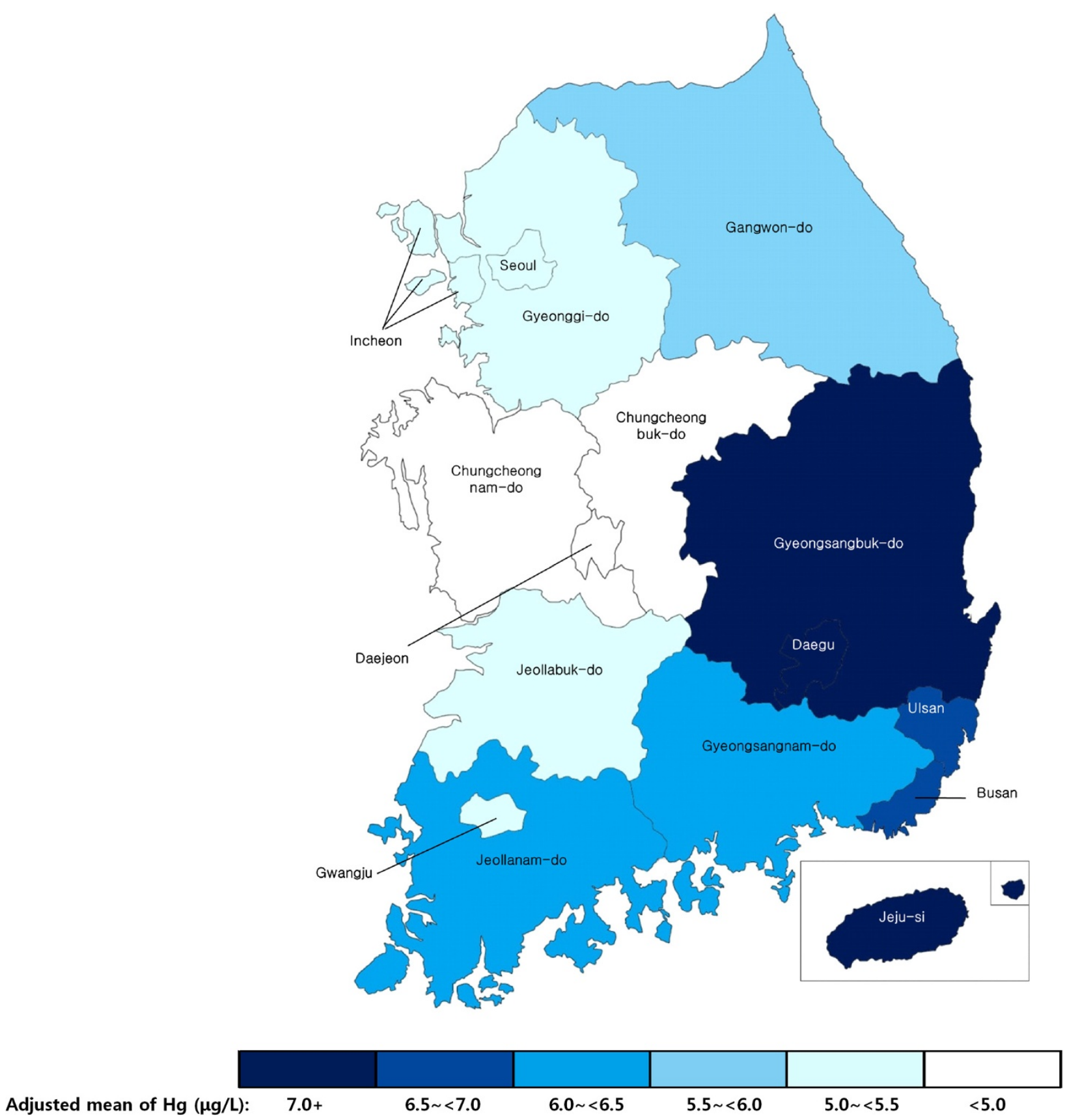

Figure 1 Adjusted blood mercury levels in Korean adults. Adjusted for age, sex, BMl, fish intake level (g/day), frequency of eating-out, physical activity, smoking status, alcohol intake, and income.

relationships. Geographic variation was also a significant determinant and our results suggest that local specific dietary habits, water, or soil may explain regional differences in WBHg levels. As expected, fish consumption was clearly the key determinant of $\mathrm{Hg}$ concentration, but together our results indicate that a dietary guideline to simply avoid certain types of fish may not reduce WBHg levels in the Korean population. Although evidence has emphasized that the benefit of fish consumption outweighs the risk posed by $\mathrm{Hg}$ exposure, these risk-benefit effects might vary, depending on the range of $\mathrm{Hg}$ exposure in the population. Thus, large-scale prospective studies with detailed dietary information, especially fish and seafood items, are warranted to make a definitive conclusion.

\section{Competing interests}

The authors declare that they have no competing interests. 


\section{Authors' contributions}

SC developed the study design, conducted the analysis, and wrote the draft of manuscript. DRJ contributed discussion, and reviewed and edited the manuscript. KP developed the study design, conducted the analysis, contributed discussion, and reviewed and edited the manuscript. All authors read and approved the final manuscript.

\section{Acknowledgements}

This study was supported by a Yeungnam University research grant in 2012 The authors thank Ms. Hyo-Jin Kim for her help on the data cleaning and analysis of this manuscript.

\section{Author details}

${ }^{1}$ College of Veterinary Medicine and Research Institute for Veterinary Science, Seoul National University, Seoul, Republic of Korea. ${ }^{2}$ Division of Epidemiology and Community Health, School of Public Health, University of Minnesota, Minneapolis, MN, USA. ${ }^{3}$ Department of Food and Nutrition, Yeungnam University, Gyeongsan, Gyeongbuk, Republic of Korea.

\section{Received: 21 November 2013 Accepted: 23 May 2014}

Published: 29 May 2014

\section{References}

1. York R, Gossard MH: Cross-national meat and fish consumption: exploring the effects of modernization and ecological context. Ecol Econ 2004 48(3):293-302.

2. Kearney J: Food consumption trends and drivers. Philos Trans $R$ Soc Lond $B$ Biol Sci 2010, 365(1554):2793-2807.

3. Livestock and fish primary equivalent. [http://faostat.fao.org/site/617/default. aspx\#ancor]. Accessed June 6, 2014

4. Mahaffey KR, Clickner RP, Jeffries RA: Adult women's blood mercury concentrations vary regionally in the United States: association with patterns of fish consumption (NHANES 1999-2004). Environ Health Perspect 2009, 117(1):47-53

5. Airey D: Total mercury concentrations in human hair from 13 countries in relation to fish consumption and location. Sci Total Environ 1983, 31(2):157-180.

6. Lee CC, Chang JW, Huang HY, Chen HL: Factors influencing blood mercury levels of inhabitants living near fishing areas. Sci Total Environ 2012, 424:316-321.

7. Schober SE, Sinks TH, Jones RL, Bolger PM, McDowell M, Osterloh J, Garrett ES, Canady RA, Dillon CF, Sun Y, Joseph CB, Mahaffey KR: Blood mercury levels in US children and women of childbearing age, 1999-2000. JAMA 2003, 289(13):1667-1674

8. Caldwell KL, Mortensen ME, Jones RL, Caudill SP, Osterloh JD: Total blood mercury concentrations in the U.S. population: 1999-2006. Int J Hyg Environ Health 2009, 212(6):588-598.

9. Xue J, Zartarian VG, Liu SV, Geller AM: Methyl mercury exposure from fish consumption in vulnerable racial/ethnic populations: probabilistic SHEDS Dietary model analyses using 1999-2006 NHANES and 1990-2002 TDS data. Sci Total Environ 2012, 414:373-379.

10. Ho MK, Lim YW, Lim JH, Yang JY, Shin DC: Association between blood mercury concentration and factor of health/life. J Environ Toxicol 2006, 21(3):229-238

11. Cha CW, Kim KJ, Yum YT: A study on the mercury contamination sources and risk for occupational mercury poisoning of mercury exposed workers in Korea. The Kor J of Occup Med 1992, 4(1):92-104.

12. Kim CY, Kim KJ, Hong D: A study on the blood zinc-protoporphyrin and serum cholinesterase activity of workers exposed to mercury vapor. Korean Ind Hyg Assoc J 1993, 3(1):62-67.

13. Shin S-R, Han AL: Improved chronic fatigue symptoms after removal of mercury in patient with increased mercury concentration in hair toxic mineral assay: a case. Korean J Fam Med 2012, 33(5):320-325.

14. Kim CW, Kim YW, Chae CH, Son JS, Park SH, Koh JC, Kim DS: The effects of the frequency of fish consumption on the blood mercury levels in Koreans. Korean J Occup Environ Med 2010, 22(2):114-121.

15. Jo EM, Kim BG, Kim YM, Yu SD, You CH, Kim JY, Hong YS: Blood mercury concentration and related factors in an urban coastal area in Korea. J Prev Med Public Health 2010, 43(5):377-386.

16. CW K, Kim YW, Chae CH, Son JS, Kim JH, Park HO, Kang YS, Kim JR, Hong YS, Kim DS, Jeong BG: The Relationship between Fish Consumption and
Blood Mercury Levels in Residents of Busan Metropolitan City and Gyeongnam Province. J Agric Med Community Health 2012, 37(4):223-232.

17. Kim NS, Lee BK: Blood total mercury and fish consumption in the Korean general population in KNHANES III, 2005. Sci Total Environ 2010, 408(20):4841-4847

18. Kim YA, Kim YN, Cho KD, Kim MY, Kim EJ, Baek OH, Lee BH: Blood heavy metal concentrations of Korean adults by seafood consumption frequency: Using the KNHANES IV. Korean J Nutr 2011, 44(6):518-526.

19. You CH, Kim BG, Kim JM, Yu SD, Kim YM, Kim RB, Hong YS: Relationship between blood mercury concentration and waist-to-hip ratio in elderly Korean individuals living in coastal areas. J Prev Med Public Health 2011, 44(5):218-225.

20. Korean Centers for Disease Control and Prevention: The Fourth Korea National Health and Nutrition Examination Survey (KNHANES IV), 2007-2009. Seoul, South Korea: Korean Centers for Disease Control and Prevention; 2010.

21. Thomson B, Lee L: Mercury content in imported fin fish. Institute of Environmental Science and Research: Christchurch, NEW ZEALAND; 2009.

22. Groth E 3rd: Ranking the contributions of commercial fish and shellfish varieties to mercury exposure in the United States: implications for risk communication. Environ Res 2010, 110(3):226-236.

23. Ainsworth BE, Haskell WL, Leon AS, Jacobs DR Jr, Montoye HJ, Sallis JF, Paffenbarger RS Jr: Compendium of physical activities: classification of energy costs of human physical activities. Med Sci Sports Exerc 1993, 25(1):71-80

24. WHO/IASO/IOTF: The Asia-Pacific Perspective: Redefining obesity and its treatment. Melbourne, Australia: WHO/IASO/IOTF; 2000. http://www.wpro.who. int/nutrition/documents/Redefining_obesity/en/. Accessed June 6, 2014.

25. Park S, Lee BK: Strong positive associations between seafood, vegetables, and alcohol with blood mercury and urinary arsenic levels in the Korean adult population. Arch Environ Contam Toxicol 2013, 64(1):160-170.

26. Mozaffarian D, Rimm EB: Fish intake, contaminants, and human health: evaluating the risks and the benefits. JAMA 2006, 296(15):1885-1899.

27. Hightower JM, Moore D: Mercury levels in high-end consumers of fish Environ Health Perspect 2003, 111(4):604-608

28. Yess NJ: U.S. Food and Drug Administration survey of methyl mercury in canned tuna. J AOAC Int 1993, 76(1):36-38.

29. Burger J, Gochfeld M: Mercury in canned tuna: white versus light and temporal variation. Environ Res 2004, 96(3):239-249.

30. Airaksinen R, Turunen AW, Rantakokko P, Mannisto S, Vartiainen T, Verkasalo PK: Blood concentration of methylmercury in relation to food consumption. Public Health Nutr 2011, 14(3):480-489.

31. Mozaffarian D, Shi P, Morris JS, Spiegelman D, Grandjean P, Siscovick DS, Willett WC, Rimm EB: Mercury exposure and risk of cardiovascular disease in two U.S. cohorts. N Engl J Med 2011, 364(12):1116-1125.

32. Barbosa AC, Jardim W, Dorea JG, Fosberg B, Souza J: Hair mercury speciation as a function of gender, age, and body mass index in inhabitants of the Negro River basin, Amazon, Brazil. Arch Environ Contam Toxicol 2001, 40(3):439-444.

doi:10.1186/1471-2458-14-527

Cite this article as: Cho et al:: Population correlates of circulating mercury levels in Korean adults: the Korea National Health and Nutrition Examination Survey IV. BMC Public Health 2014 14:527.

\section{Submit your next manuscript to BioMed Central and take full advantage of:}

- Convenient online submission

- Thorough peer review

- No space constraints or color figure charges

- Immediate publication on acceptance

- Inclusion in PubMed, CAS, Scopus and Google Scholar

- Research which is freely available for redistribution 